\title{
Kajian Kawasan Strategis Cepat Tumbuh Kabupaten Bima
}

\author{
*Fariz Primadi Hirsan, Ima Rahmawati Sushanti, Baiq Harly Widayanti
}

Perencanaan Wilayah dan Kota, Universitas Muhammadiyah Mataram

fariz.primadi@gmail.com

\begin{tabular}{l} 
INFO ARTIKEL \\
\hline Riwayat Artikel: \\
Diterima:23-5-2019 \\
Disetujui:26-6-2019 \\
\hline
\end{tabular}

Kata Kunci:

Identifikasi

Kawasan Strategis

Cepat Tumbuh

\section{A. LATAR BELAKANG}

Perencanaan Pengembangan Kawasan Strategis Cepat Tumbuh (KSCT) merupakan salah satu dokumen perencanaan pengembangan di daerah yang diamanatkan dalam Permendagri Nomor 29 Tahun 2008 tentang Pengembangan Kawasan Strategis dan Cepat Tumbuh di daerah (KSCT). Rencana induk ini disusun dalam kurun waktu 5 (lima) tahunan yang memuat hasil kajian secara menyeluruh (komprehensif) dan terpadu terhadap semua aspek kunci, pengembangan kawasan kawasan strategis cepat tumbuh sebagai data dasar serta proyeksi arah, skenario, dan tahapan pengembangan KSCT dalam jangka menengah. [1] Permendagri Nomor 29 Tahun 2008 memberikan salah satu pilihan bagi daerah untuk membangun daerahnya melalui pendekatan pengembangan daerahnya berupa Kawasan Strategis dan Cepat Tumbuh (KSCT), yang sesuai dengan kondisi, kekhasan, dan potensi unggulan daerah yang pada akhirnya mampu memperkuat daya saing perekonomian. Permendagri hanya merupakan sarana untuk pendorong percepatan pengembangan kawasan yang berpotensi sebagai pusat pertumbuhan wilayah yang telah berkembang atau potensial berkembang, mengurangi kesenjangan pembangunan antar wilayah dan mendorong daerah perbatasan, pesisir dan pulau-pulau kecil, serta mengoptimalkan pemanfaatan komparatif dan kompetitif sektor/produk unggulan daerah dan daya tarik kawasan di pasar lokal maupun domestik. [2]

Menurut Rustiadi (2006) wilayah dapat didefinisikan sebagai unit geografis dengan batas-batas spesifik tertentu dimana komponen-komponen wilayah tersebut satu sama lain saling berinteraksi secara fungsional. Sehingga batasan wilayah tidaklah selalu bersifat fisik dan pasti, tetapi seringkali bersifat dinamis. [3] Komponen-komponen wilayah mencakup komponen biofisik alam, sumberdaya buatan (infrastruktur), manusia serta bentuk-bentuk kelembagaan. Dengan demikian istilah wilayah menekankan interaksi antar 
32|Jurnal Planoearth | Vol.4, No.1, Februari 2019, hal 31-.42

manusia dengan sumberdaya-sumberdaya lainnya yang ada di dalam suatu batasan unit geografis tertentu.

Seiring perkembangan dan pertumbuhan wilayah Kabupaten Bima serta pemanfaatan ruang yang tidak terkendali sehingga terbentuk pusat-pusat pertumbuhan baru yang tersebar diberbagai wilayah kabupaten. Dalam rangka mendorong percepatan pengembangan kawasan tersebut, mengurangi kesenjangan pembangunan antar wilayah, dan mendorong pertumbuhan daerah yang masih tertinggal dan perbatasan di Kabupaten Bima, sehingga diperlukan identifikasi Kawasan Strategis Cepat Tumbuh di Kabupaten Bima. Sasaran dalam penelitian ini adalah mengidentifikasi Kawasan Strategis Cepat Tumbuh (KSCT) Kabupaten Bima, merumuskan rencana pusat-pusat pelayanan kawasan dalam wilayah Kabupaten Bima, dan merumuskan rencana pengembangan kawasan strategis cepat tumbuh Kabupaten Bima.

Adapun yang menjadi wilayah identifikasi Kawasan Strategis Cepat Tumbuh (KSCT) adalah seluruh desa dan kecamatan yang ada di Kabupaten Bima. Kabupaten Bima merupakan salah satu kabupaten yang ada di Provinsi Nusa Tenggara Barat. Berikut adalah desa dan kecamatan yang merupakan wilayah identifikasi Kawasan Strategis Cepat Tumbuh Kabupaten Bima.

TABEL 1

\begin{tabular}{|c|c|c|}
\hline No & Kecamatan & Desa \\
\hline & & 6 Tambe \\
\hline & & $7 \quad$ Rasabou \\
\hline & & 8 Rato \\
\hline & & $9 \quad$ Kananga \\
\hline & & 10 Nggembe \\
\hline & & 11 Tumpu \\
\hline & & 12 Rada \\
\hline & & 13 Darussalam \\
\hline & & 14 Kara \\
\hline 4 & Madapangga & 1 Woro \\
\hline & & 2 Campa \\
\hline & & $3 \quad$ Mpuri \\
\hline & & $4 \quad$ Dena \\
\hline & & $5 \quad$ Rade \\
\hline & & $6 \quad$ Monggo \\
\hline & & $7 \quad$ Ndano \\
\hline & & 8 Tonda \\
\hline & & $9 \quad$ Bolo \\
\hline & & 10 Mada Dau \\
\hline & & 11 Ncandi \\
\hline
\end{tabular}

Wilayah Identifikasi

\begin{tabular}{|c|c|c|}
\hline No & Kecamatan & Desa \\
\hline \multirow[t]{14}{*}{$\mathbf{1}$} & \multirow[t]{14}{*}{ Monta } & Tolotangga \\
\hline & & $2 \quad$ Sondo \\
\hline & & $3 \quad$ Simpasai \\
\hline & & $4 \quad$ Sie \\
\hline & & $5 \quad$ Tangga \\
\hline & & $6 \quad$ Sakuru \\
\hline & & 7 Monta \\
\hline & & 8 Baralau \\
\hline & & 9 Tangga Baru \\
\hline & & $10 \quad$ Tolouwi \\
\hline & & 11 Wilamaci \\
\hline & & 12 Pela \\
\hline & & 13 Nontotera \\
\hline & & $14 \quad$ Waro \\
\hline \multirow[t]{5}{*}{2} & \multirow[t]{5}{*}{ Parado } & $1 \quad$ Lere \\
\hline & & $2 \quad$ Paradowane \\
\hline & & $3 \quad$ Kuta \\
\hline & & $4 \quad$ Paradorato \\
\hline & & $5 \quad$ Kanca \\
\hline \multirow[t]{5}{*}{3} & \multirow[t]{5}{*}{ Bolo } & $1 \quad$ Sanolo \\
\hline & & $2 \quad$ Sondosia \\
\hline & & $3 \quad$ Bontokape \\
\hline & & 4 Timu \\
\hline & & $5 \quad$ Leu \\
\hline
\end{tabular}

\begin{tabular}{|c|c|c|c|}
\hline \multirow[t]{15}{*}{5} & \multirow[t]{15}{*}{ Woha } & 1 & Keli \\
\hline & & 2 & Tenga \\
\hline & & 3 & Naru \\
\hline & & 4 & Nisa \\
\hline & & 5 & Tente \\
\hline & & 6 & Rakabodo \\
\hline & & 7 & Samili \\
\hline & & 8 & Kalampa \\
\hline & & 9 & Risa \\
\hline & & 10 & Pandai \\
\hline & & 11 & Donggobolo \\
\hline & & 12 & Dadibou \\
\hline & & 13 & Talabiu \\
\hline & & 14 & Waduwani \\
\hline & & 15 & Penapali \\
\hline \multirow[t]{9}{*}{6} & \multirow[t]{9}{*}{ Belo } & 1 & Ncera \\
\hline & & 2 & Lido \\
\hline & & 3 & Ngali \\
\hline & & 4 & Renda \\
\hline & & 5 & Cenggu \\
\hline & & 6 & Runggu \\
\hline & & 7 & Soki \\
\hline & & 8 & Roka \\
\hline & & 9 & Diha \\
\hline \multirow[t]{3}{*}{7} & \multirow[t]{3}{*}{ Palibelo } & 1 & Roi \\
\hline & & 2 & Nata \\
\hline & & 3 & Ntonggu \\
\hline
\end{tabular}




\begin{tabular}{|c|c|c|}
\hline \multirow[t]{10}{*}{ No } & \multirow[t]{10}{*}{ Kecamatan } & Desa \\
\hline & & $4 \quad$ Teke \\
\hline & & $5 \quad$ Tonggorisa \\
\hline & & $6 \quad$ Belo \\
\hline & & $7 \quad$ Panda \\
\hline & & $8 \quad$ Dore \\
\hline & & 9 Tonggondoa \\
\hline & & $10 \quad$ Ragi \\
\hline & & 11 Padolo \\
\hline & & 12 Bre \\
\hline \multirow[t]{9}{*}{8} & \multirow[t]{9}{*}{ Wawo } & $1 \quad$ Tarlawi \\
\hline & & 2 Raba \\
\hline & & $3 \quad$ Pesa \\
\hline & & $4 \quad$ Ntori \\
\hline & & $5 \quad$ Maria \\
\hline & & $6 \quad$ Kambilo \\
\hline & & $7 \quad$ Kombo \\
\hline & & 8 Maria Utara \\
\hline & & $9 \quad$ Riamau \\
\hline \multirow[t]{18}{*}{9} & \multirow[t]{18}{*}{ Langgudu } & $1 \quad$ UPT Laju \\
\hline & & $2 \quad$ Laju \\
\hline & & $3 \quad$ UPT Doro O'o \\
\hline & & $4 \quad$ Doro O'o \\
\hline & & $5 \quad$ UPT Waworada \\
\hline & & $6 \quad$ Waworada \\
\hline & & $7 \quad$ Kawuwu \\
\hline & & $8 \quad$ Karumbu \\
\hline & & $9 \quad$ Kalodu \\
\hline & & $10 \quad$ Rupe \\
\hline & & $11 \quad$ Kangga \\
\hline & & 12 Karampi \\
\hline & & 13 Waduruka \\
\hline & & 14 Dumu \\
\hline & & $15 \quad$ Rompo \\
\hline & & 16 Sambane \\
\hline & & 17 Sarae Ruma \\
\hline & & $18 \quad$ Pusu \\
\hline \multirow[t]{6}{*}{10} & \multirow[t]{6}{*}{ Lambitu } & $1 \quad$ Sambori \\
\hline & & $2 \quad$ Kaboro \\
\hline & & $3 \quad$ Kuta \\
\hline & & $4 \quad$ Teta \\
\hline & & $5 \quad$ Kaowa \\
\hline & & $6 \quad$ Londu \\
\hline \multirow[t]{4}{*}{11} & \multirow[t]{4}{*}{ Sape } & $\begin{array}{ll}1 & \text { Sari }\end{array}$ \\
\hline & & $2 \quad$ Boke \\
\hline & & $3 \quad$ Jia \\
\hline & & $4 \quad$ Naru \\
\hline
\end{tabular}

\begin{tabular}{|c|c|c|}
\hline \multirow[t]{15}{*}{ No } & \multirow[t]{15}{*}{ Kecamatan } & Desa \\
\hline & & $5 \quad$ Bajopulau \\
\hline & & $6 \quad$ Bugis \\
\hline & & $7 \quad$ Rasabou \\
\hline & & $8 \quad \mathrm{Nae}$ \\
\hline & & 9 Parangina \\
\hline & & $10 \quad$ Rai Oi \\
\hline & & $11 \quad$ Sangia \\
\hline & & 12 Kowo \\
\hline & & 13 Buncu \\
\hline & & 14 Poja \\
\hline & & 15 Tanah Putih \\
\hline & & 16 Naru Barat \\
\hline & & 17 Lamere \\
\hline & & 18 Oi Maci \\
\hline \multirow[t]{14}{*}{12} & Lambu & 1 Mangge \\
\hline & & $2 \quad$ Nggelu \\
\hline & & $3 \quad$ Lambu \\
\hline & & $4 \quad$ Soro \\
\hline & & $5 \quad$ Sumi \\
\hline & & $6 \quad$ Rato \\
\hline & & $7 \quad$ Lanta \\
\hline & & $8 \quad$ Simpasai \\
\hline & & $9 \quad$ Kaleo \\
\hline & & 10 Hidirasa \\
\hline & & $11 \quad$ Melayu \\
\hline & & 12 Lanta Barat \\
\hline & & 13 Monta Baru \\
\hline & & 14 Sangga \\
\hline \multirow[t]{14}{*}{13} & Wera & $1 \quad$ Ntoke \\
\hline & & $2 \quad$ Pai \\
\hline & & $3 \quad$ Bala \\
\hline & & $4 \quad$ Oi Tui \\
\hline & & $5 \quad$ Tawali \\
\hline & & $6 \quad$ Sangiang \\
\hline & & $7 \quad$ Hidirasa \\
\hline & & 8 Tadewa \\
\hline & & $9 \quad$ Nunggi \\
\hline & & 10 Wora \\
\hline & & 11 Nangga Wera \\
\hline & & 12 Kalajena \\
\hline & & 13 Ranggasolo \\
\hline & & $14 \quad$ Mandala \\
\hline \multirow[t]{4}{*}{14} & Ambalawi & $1 \quad$ Rite \\
\hline & & 2 Tolowata \\
\hline & & $3 \quad$ Talapiti \\
\hline & & $4 \quad$ Nipa \\
\hline
\end{tabular}




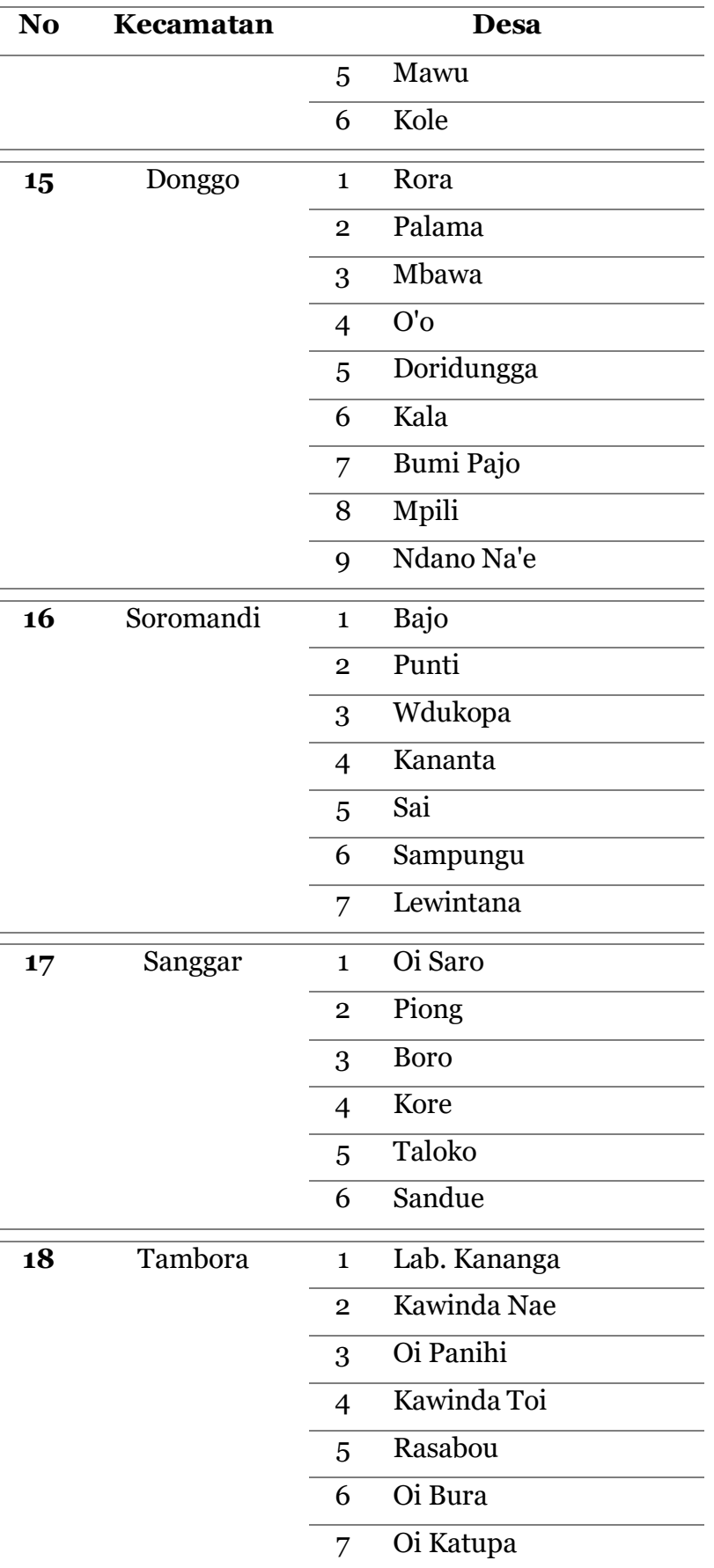

Sumber : Kecamatan dalam Angka Kabupaten Bima, 2017

Istilah pendekatan Wilayah Strategis dan Cepat Tumbuh menurut Undang-Undang Nomor 26 Tahun 2007 didefinisikan sebagai wilayah yang penataan ruangnya diprioritaskan karena mempunyai pengaruh sangat penting terhadap kedaulatan negara, pertahanan dan keamanan negara, ekonomi, sosial, budaya, dan lingkungan. [4] Sedangkan, Kawasan Strategis Cepat Tumbuh (KSCT) adalah merupakan bagian kawasan strategis yang telah berkembang atau potensial untuk dikembangkan karena memiliki keunggulan sumber daya dan geografis yang dapat menggerakkan pertumbuhan ekonomi wilayah sekitarnya. Hakikat pembangunan daerah dapat dikelompokkan pada 2 (dua) yaitu, pendekatan sektoral dan pendekatan kewilayahan. Pendekatan pengembangan wilayah strategis dan cepat tumbuh menjadi harapan dalam mendorong pengembangan wilayah sekitarnya (dalam arti bahwa wilayah sekitarnya adalah daerah tertinggal dan termasuk perbatasan), bertujuan meningkatkan pemerataan pembangunan antar daerah tentunya dilakukan melalui pendekatan sektoral dan kewilayahan. Dari sisi pendekatan kewilayahan, definisi wilayah strategis adalah wilayah yang secara ekonomi diharapkan mampu menjawab kebutuhan pembangunan di tingkat nasional, atau provinsi, atau kabupaten/kota.

\section{B. METODE PENELITIAN}

Penentuan Kawasan Strategis Cepat Tumbuh (KSCT) Kabupaten Bima menggunakan analisis AHP (Analysis Hierarchy Process) dan analisis isu-isu strategis perkembangan wilayah. Selanjutnya menggunakan analisis tipologi klassen untuk mempertajam pengembangan kawasan yang teridentifikasi sebagai kawasan cepat tumbuh.

\section{HASIL DAN PEMBAHASAN}

\section{Pertumbuhan Wilayah Eksisting}

Pertumbuhan wilayah eksisting (Ye) diperoleh berdasarkan nilai produksi dan nilai sistem produksi. Adapun yang termasuk pada nilai produksi adalah PDRB (Product Domestic Regional Bruto) dan KK Miskin, sedangkan yang termasuk nilai sistem produksi adalah produksi (UMKM, IBM, angkatan kerja, dan usaha pariwisata), transaksi (sarana perdagangan dan niaga), dan transformasi (tenaga kerja sektor primer dan tenaga kerja sektor non primer). Berikut adalah nilai produksi (z) dan nilai sistem produksi (y) masing-masing kecamatan di Kabupaten Bima.

TABEL 2

Nilai Produksi \& Nilai Sistem Produksi Kabupaten Bima

\begin{tabular}{|c|c|c|c|c|c|}
\hline \multirow[t]{2}{*}{ No } & \multirow[t]{2}{*}{ Kecamatan } & \multicolumn{2}{|c|}{ Produksi (z) } & \multicolumn{2}{|c|}{$\begin{array}{c}\text { Sistem } \\
\text { Produksi (y) }\end{array}$} \\
\hline & & $\begin{array}{l}\text { Nilai } \\
\text { Total }\end{array}$ & Kelas & $\begin{array}{l}\text { Nilai } \\
\text { Total }\end{array}$ & Kelas \\
\hline $\mathbf{1}$ & Monta & 3.20 & 4 & 2.96 & 3 \\
\hline 2 & Parado & 2.60 & 1 & 1.51 & 1 \\
\hline 3 & Bolo & 3.40 & 5 & 4.14 & 5 \\
\hline 4 & Madapangga & 3.00 & 3 & 2.04 & 2 \\
\hline 5 & Woha & 3.40 & 5 & 1.73 & 1 \\
\hline 6 & Belo & 3.00 & 3 & 1.42 & 1 \\
\hline 7 & Palibelo & 3.00 & 3 & 2.32 & 2 \\
\hline 8 & Wawo & 2.80 & 2 & 1.46 & 1 \\
\hline 9 & Langgudu & 3.20 & 4 & 2.09 & 2 \\
\hline 10 & Lambitu & 2.60 & 1 & 1.11 & 1 \\
\hline 11 & Sape & 3.40 & 5 & 4.45 & 5 \\
\hline 12 & Lambu & 3.20 & 4 & 2.83 & 2 \\
\hline 13 & Wera & 3.00 & 3 & 1.34 & 1 \\
\hline 14 & Ambalawi & 2.80 & 2 & 1.37 & 1 \\
\hline
\end{tabular}




\begin{tabular}{clcccc}
\hline No & Kecamatan & \multicolumn{2}{c}{ Produksi (z) } & \multicolumn{2}{c}{$\begin{array}{c}\text { Sistem } \\
\text { Produksi (y) }\end{array}$} \\
\cline { 3 - 6 } & & $\begin{array}{l}\text { Nilai } \\
\text { Total }\end{array}$ & Kelas & \multicolumn{2}{c}{$\begin{array}{c}\text { Nilai } \\
\text { Total }\end{array}$} \\
Kelas \\
\hline 15 & Donggo & 2.80 & 2 & 1.48 & 1 \\
\hline 16 & Soromadi & 2.80 & 2 & 1.68 & 1 \\
\hline 17 & Sanggar & 2.80 & 2 & 1.26 & 1 \\
\hline 18 & Tambora & 2.60 & 1 & 1.20 & 1 \\
\hline
\end{tabular}

Sumber : Hasil analisis, 2018

Kecamatan yang berhasil menghasilkan produk yang memiliki nilai jual tinggi dengan sistem produksi yang efektif dan efisien adalah sebagai berikut.

TABEL 3

Pertumbuhan Wilayah Eksisting

Kabupaten Bima

\begin{tabular}{|c|c|c|c|c|}
\hline No & Kecamatan & $\begin{array}{c}\begin{array}{c}\text { Nilai } \\
\text { Produksi }\end{array} \\
(z)\end{array}$ & $\begin{array}{c}\text { Nilai Sistem } \\
\text { Produksi }\end{array}$ & Ye \\
\hline $\mathbf{1}$ & Monta & 4 & 3 & 1 \\
\hline 2 & Parado & 1 & 1 & O \\
\hline 3 & Bolo & 5 & 5 & O \\
\hline 4 & Madapangga & 3 & 2 & 1 \\
\hline 5 & Woha & 5 & 1 & 4 \\
\hline 6 & Belo & 3 & 1 & 2 \\
\hline 7 & Palibelo & 3 & 2 & 1 \\
\hline 8 & Wawo & 2 & 1 & 1 \\
\hline 9 & Langgudu & 4 & 2 & 2 \\
\hline 10 & Lambitu & 1 & 1 & O \\
\hline 11 & Sape & 5 & 5 & $\mathrm{O}$ \\
\hline 12 & Lambu & 4 & 2 & 2 \\
\hline 13 & Wera & 3 & 1 & 2 \\
\hline 14 & Ambalawi & 2 & 1 & 1 \\
\hline 15 & Donggo & 2 & 1 & 1 \\
\hline 16 & Soromadi & 2 & 1 & 1 \\
\hline 17 & Sanggar & 2 & 1 & 1 \\
\hline 18 & Tambora & 1 & 1 & O \\
\hline
\end{tabular}

Sumber : Hasil analisis, 2018

3 (tiga) nilai tertinggi dinyatakan sebagai pertumbuhan wilayah eksisting adalah :

- Kecamatan Woha = Nilai 4

- Kecamatan Belo, Kecamatan Langgudu, Kecamatan Lambu, dan Kecamatan Wera = Nilai 2

- Kecamatan Monta, Kecamatan Madapangga, Kecamatan Palibelo, Kecamatan Wawo, Kecamatan Ambalawi, Kecamatan Donggo, Kecamatan Soromandi, dan Kecamatan Sanggar = Nilai 1.

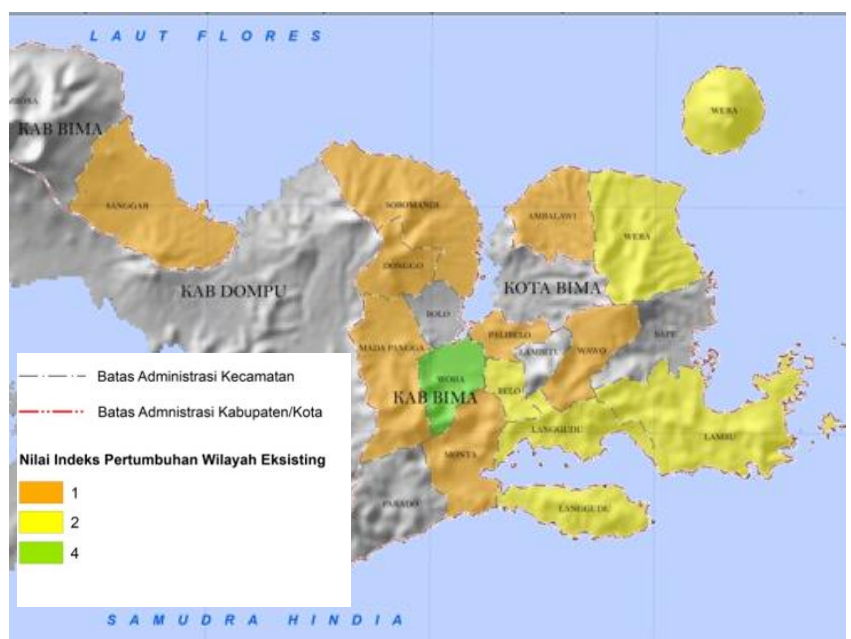

Gambar 1. Indeks Pertumbuhan Wilayah Eksisting Sumber : Hasil analisis,2018

\section{Pertumbuhan Wilayah Potensial}

Pertumbuhan wilayah potensial (Yp) diperoleh berdasarkan nilai sistem produksi dan nilai potensi. Adapun yang termasuk pada nilai sistem produksi adalah produksi (UMKM, IBM, angkatan kerja, dan usaha pariwisata), trasaksi (sarana perdagangan dan niaga), dan transformasi (tenaga kerja sektor primer dan tenaga kerja sektor non primer), sedangkan yang termasuk nilai potensi adalah potensi Sumber Daya Alam (perikanan, pertanian, peternakan, wisata, kerawanan bencana, dan kesesuaian lahan), potensi Sumber Daya Manusia (tingkat pendidikan, partisipasi masyarakat dalam lembaga ekonomi, jumlah kelompok tani, dan penduduk usia produktif), infrastruktur (jalan, sarana pendidikan, sarana kesehatan, prasarana listrik, dan prasarana air), dan pendanaan (alokasi dana desa). Berikut adalah nilai sistem produksi (y) dan nilai potensi (x) masing-masing kecamatan di Kabupaten Bima.

TABEL 4

Nilai Sistem Produksi \& Nilai Potensi Kabupaten Bima

\begin{tabular}{clcccc}
\hline No & Kecamatan & \multicolumn{2}{c}{$\begin{array}{c}\text { Sistem } \\
\text { Produksi (y) }\end{array}$} & \multicolumn{2}{c}{ Potensi (x) } \\
\cline { 3 - 6 } & & $\begin{array}{l}\text { Nilai } \\
\text { Total }\end{array}$ & Kelas & $\begin{array}{c}\text { Nilai } \\
\text { Total }\end{array}$ & Kelas \\
\hline $\mathbf{1}$ & Monta & 2.96 & 3 & 2.69 & 4 \\
\hline $\mathbf{2}$ & Parado & 1.51 & 1 & 1.65 & 1 \\
\hline $\mathbf{3}$ & Bolo & 4.14 & 5 & 2.72 & 5 \\
\hline $\mathbf{4}$ & Madapangga & 2.04 & 2 & 2.57 & 4 \\
\hline $\mathbf{5}$ & Woha & 1.73 & 1 & 2.44 & 4 \\
\hline $\mathbf{6}$ & Belo & 1.42 & 1 & 2.08 & 3 \\
\hline 7 & Palibelo & 2.32 & 2 & 2.26 & 3 \\
\hline $\mathbf{8}$ & Wawo & 1.46 & 1 & 2.04 & 2 \\
\hline $\mathbf{9}$ & Langgudu & 2.09 & 2 & 2.63 & 4 \\
\hline $\mathbf{1 0}$ & Lambitu & 1.11 & 1 & 1.38 & 1 \\
\hline $\mathbf{1 1}$ & Sape & 4.45 & 5 & 3.01 & 5 \\
\hline $\mathbf{1 2}$ & Lambu & 2.83 & 2 & 2.81 & 5 \\
\hline & & & & &
\end{tabular}




\begin{tabular}{lllccc}
\hline No & Kecamatan & \multicolumn{2}{c}{$\begin{array}{c}\text { Sistem } \\
\text { Produksi (y) }\end{array}$} & \multicolumn{2}{c}{ Potensi (x) } \\
\cline { 3 - 6 } & $\begin{array}{l}\text { Nilai } \\
\text { Total }\end{array}$ & Kelas & $\begin{array}{c}\text { Nilai } \\
\text { Total }\end{array}$ & Kelas \\
\hline 13 & Wera & 1.34 & 1 & 2.79 & 5 \\
\hline 14 & Ambalawi & 1.37 & 1 & 1.82 & 2 \\
\hline 15 & Donggo & 1.48 & 1 & 2.26 & 3 \\
\hline 16 & Soromadi & 1.68 & 1 & 2.29 & 3 \\
\hline 17 & Sanggar & 1.26 & 1 & 2.05 & 3 \\
\hline 18 & Tambora & 1.20 & 1 & 1.80 & 2 \\
\hline
\end{tabular}

Sumber : Hasil analisis, 2018

Kecamatan yang berhasil memanfaatkan potensi yang ada dengan sistem produksi yang efektif dan efisien adalah sebagai berikut.

TABEL 5

Pertumbuhan Nilai Potensial Kabupaten Bima

\begin{tabular}{|c|c|c|c|c|}
\hline No & Kecamatan & $\begin{array}{c}\begin{array}{c}\text { Nilai } \\
\text { Sistem } \\
\text { Produksi }\end{array} \\
(y)\end{array}$ & $\begin{array}{c}\text { Nilai } \\
\text { Potensi }\end{array}$ & $\mathbf{Y p}$ \\
\hline $\mathbf{1}$ & Monta & 3 & 4 & -1 \\
\hline 2 & Parado & 1 & 1 & $\mathrm{O}$ \\
\hline 3 & Bolo & 5 & 5 & $\mathrm{O}$ \\
\hline 4 & Madapangga & 2 & 4 & -2 \\
\hline 5 & Woha & 1 & 4 & -3 \\
\hline 6 & Belo & 1 & 3 & -2 \\
\hline 7 & Palibelo & 2 & 3 & -1 \\
\hline 8 & Wawo & 1 & 2 & -1 \\
\hline 9 & Langgudu & 2 & 4 & -2 \\
\hline 10 & Lambitu & 1 & 1 & $\mathrm{O}$ \\
\hline $\mathbf{1 1}$ & Sape & 5 & 5 & o \\
\hline 12 & Lambu & 2 & 5 & -3 \\
\hline 13 & Wera & 1 & 5 & -4 \\
\hline 14 & Ambalawi & 1 & 2 & -1 \\
\hline 15 & Donggo & 1 & 3 & -2 \\
\hline 16 & Soromadi & 1 & 3 & -2 \\
\hline 17 & Sanggar & 1 & 3 & -2 \\
\hline 18 & Tambora & 1 & 2 & -1 \\
\hline
\end{tabular}

Sumber : Hasil analisis, 2018

2 (dua) nilai tertinggi dinyatakan sebagai pertumbuhan wilayah potensial adalah :

- Kecamatan Parado, Kecamatan Bolo, Kecamatan Lambitu, dan Kecamatan Sape = Nilai o

- Kecamatan Monta, Kecamatan Palibelo, Kecamatan Wawo, Kecamatan Ambalawi, dan Kecamatan Tambora $=$ Nilai -1

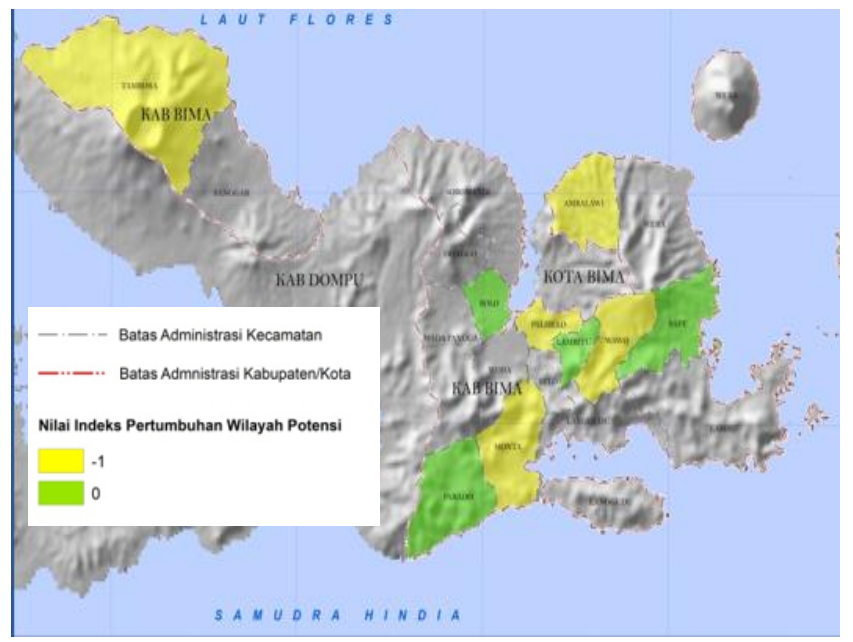

Gambar 2. Indeks Pertumbuhan Wilayah Potensi Sumber : Hasil analisis,2018

\section{Identifikasi Kawasan Strategis Cepat Tumbuh Kabupaten Bima}

Kawasan Strategis Cepat Tumbuh Kabupaten Bima di tentukan berdasarkan pada hasil penggabungan kelas masing-masing kecamatan pada Indeks Pertumbuhan Wilayah Eksisting dengan Indeks Pertumbuhan Wilayah Potensial yang dimana indeks pertumbuhan wilayah potensial merupakan wilayah yang berhasil memanfaatkan potensi yang ada dengan sistem produksi yang efektif dan efisien sedangkan indeks pertumbuhan wilayah eksisting merupakan wilayah yang berhasil menghasilkan produk yang memiliki nilai jual tinggi dengan sistem produksi yang efektif dan efisien adapun wilayah yang masuk dalam kategori kelas 1 dari hasil penggabungan kelas masing-masing yaitu Kecamatan Woha sedangkan wilayah yang masuk Kelas o yaitu Kecamatan Monta, Kecamatan Parado, Kecamatan Bolo, Kecamatan Belo, Kecamatan Palibelo, Kecamatan Wawo, Kecamatan Langgudu, Kecamatan Lambitu,Kecamatan Sape, Kecamatan Lambu, Kecamatan Ambalawi, Kecamatan Tambora, Kecamatan Sanggar.

TABEL 6

Kawasan Strategis Cepat Tumbuh Kabupaten Bima Berdasarkan Pertumbuhan Wilayah Eksisting Dan Potensial

\begin{tabular}{clccc} 
No & Kecamatan & Ye & Yp & KSCT \\
\hline $\mathbf{1}$ & Monta & 1 & -1 & 0 \\
\hline $\mathbf{2}$ & Parado & 0 & 0 & 0 \\
\hline $\mathbf{3}$ & Bolo & 0 & 0 & 0 \\
\hline $\mathbf{4}$ & Madapangga & 1 & -2 & -1 \\
\hline $\mathbf{5}$ & Woha & 4 & -3 & 1 \\
\hline $\mathbf{6}$ & Belo & 2 & -2 & 0 \\
\hline 7 & Palibelo & 1 & -1 & 0 \\
\hline $\mathbf{8}$ & Wawo & 1 & -1 & 0 \\
\hline $\mathbf{9}$ & Langgudu & 2 & -2 & 0 \\
\hline $\mathbf{1 0}$ & Lambitu & 0 & 0 & 0 \\
\hline
\end{tabular}




\begin{tabular}{|c|c|c|c|c|}
\hline No & Kecamatan & Ye & Yp & KSCT \\
\hline 11 & Sape & o & o & $\mathrm{O}$ \\
\hline 12 & Lambu & 2 & -3 & -1 \\
\hline 13 & Wera & 2 & -4 & -2 \\
\hline 14 & Ambalawi & 1 & -1 & $\mathrm{O}$ \\
\hline 15 & Donggo & 1 & -2 & -1 \\
\hline 16 & Soromadi & 1 & -2 & -1 \\
\hline 17 & Sanggar & 1 & -2 & -1 \\
\hline 18 & Tambora & 0 & -1 & -1 \\
\hline
\end{tabular}

Sumber : Hasil analisis, 2018

Penentuan Kawasan Strategis Cepat Tumbuh Kabupaten Bima tidak hanya berfokus pada perhitungan menggunakan AHP (Analysis Hierarchy Process) dengan indikator-indikator yang telah ditentukan, tetapi juga melihat isu-isu strategis perkembangan wilayah Kabupaten Bima. Sehingga, selain kecamatankecamatan yang telah disebutkan pada paragraf sebelumnya muncul kecamatan lain yang berpotensi sebagai Kawasan Strategis Cepat Tumbuh yang menjadikan kecamatan tesebut memiliki nilai tambah pada perhitungan secara matematis. Adapun kecamatan yang dimaksud adalah Kecamatan Ambalawi, Kecamatan Soromandi, Kecamatan Donggo, Kecamatan Monta, Kecamatan Tambora dan Kecamatan Sanggar.

Kecamatan Tambora dan Kecamatan Sanggar merupakan kawasan pengembangan Geopark Nasional Tambora. Gunung Tambora yang terletak di Kecamatan Tambora dan Kecamatan Sanggar telah ditetapkan sebagai geopark nasional dari Komite Nasional Geopark Indonesia (KNGI) pada seminar nasional dan festifal Geopark II Pulau Belitong tahun 2017 lalu. Kawasan Gunung Tambora yang tidak hanya memiliki potensi keragaman geologi yang luar biasa juga memiliki potensi keragaman hayati dan keragaman budaya yang tentunya apabila dikelola dengan baik akan membawa manfaat bagi masyarakat. Selain berfungsi sebagai kawasan konservasi dan edukasi, penatapan Geopark Nasional Gunung Tambora diyakini dapat meningkatkan kesejahteraan dan menumbuhkan embrio ekonomi lokal melalui pengembangan sektor pariwisata berbasis kegiatan ecotourism dan agrowisata. Guna mendukung pengembangan kawasan tersebut maka kedua kecamatan ini termasuk kedalam Kawasan Strategis Cepat Tumbuh Kabupaten Bima. Berdasarkan pertimbangan-pertimbangan tersebut, maka Kawasan Strategis Cepat Tumbuh Kabupaten Bima meliputi 15 kecamatan yaitu : Kecamatan Monta, Kecamatan Bolo, Kecamatan Woha, Kecamatan Belo, Kecamatan Palibelo, Kecamatan Wawo, Kecamatan Langgudu, Kecamatan Lambitu, Kecamatan Sape, Kecamatan Lambu, Kecamatan Wera, Kecamatan Donggo, Kecamatan Soromandi, Kecamatan Sanggar, dan Kecamatan Tambora.

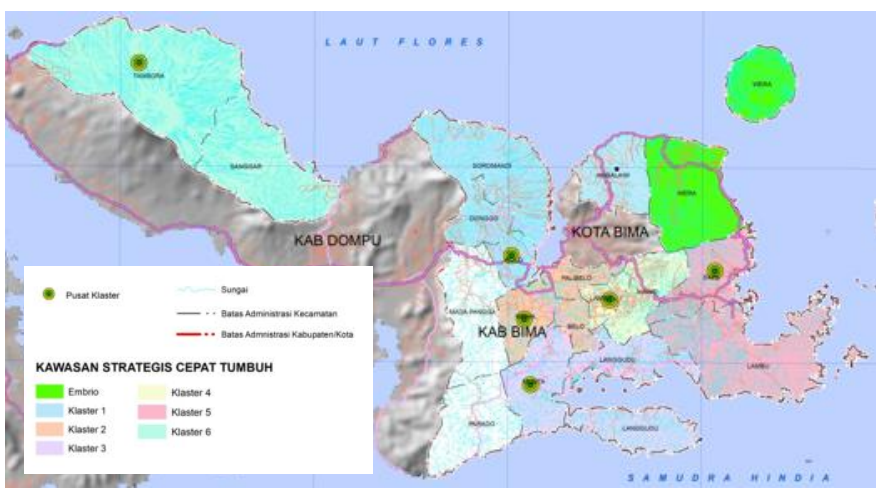

Gambar 3. Kawasan Strategis Cepat Tumbuh Sumber : Hasil analisis,2018

Pembagian Kawasan Strategis Cepat Tumbuh dilakukan dengan membagi wilayah yang sudah teridentifikasi sebagai KSCT menjadi klaster dan embrio. Wilayah dengan jenis potensi yang sama dan berdekatan menjadi satu klaster, sedangkan wilayah yang berdiri sendiri disebut embrio. Dilihat dari pembagian Kawasan Strategis Cepat Tumbuh Kabupaten Bima terbagi menjadi beberapa bagian adalah :

1) Berdasarkan dari hasil penbagian Kawasan Strategis Cepat Tumbuh Kabupaten yang termasuk dalam wilayah yang berdiri sendiri atau embrio adalah Kecamatan Wera;

2) Berdasarkan hasil pembagian Kawasan Strategis Cepat Tumbuh Kabupaten Bima yang termasuk dalam klaster 1 yaitu wilayah Kecamatan Bolo, Kecamatan Soromandi, Kecamatan Donggo;

3) Berdasarkan hasil pembagaian Kawasan Strategis Cepat Tumbuh Kabupaten Bima yang termasuk dalam Klasten 2 yaitu wilayah Kecamatan Woha, Kecamatan Palibelo, dan Kecamatan Belo;

4) Berdasarkan hasil pembagaian Kawasan Strategis Cepat Tumbuh Kabupaten Bima yang termasuk dalam Klasten 3 yaitu wilayah Kecamatan Langgudu, dan Kecamatan Monta;

5) Berdasarkan hasil pembagian Kawasan Strategis Cepat Tumbuh Kabupaten Bima yang termasuk dalam Klaster 4 yaitu wilayah Kecamatan Lambitu, Kecamatan Wawo;

6) Berdasarkan hasil pembangian Kawsan Strategis Cepat Tumbuh Kabupaten Bima yang termasuk dalam Klaster 5 yaitu wilayah Kecamatan Sape, Kecamatan Lambu, dan

7) Berdasarkan hasil pembangian Kawsan Strategis Cepat Tumbuh Kabupaten Bima yang termasuk dalam Klaster 6 yaitu wilayah Kecamatan Tambora, dan Kecamatan Sanggar.

\section{Rencana Pengembangan Embrio}

Kawasan embrio terdiri dari Kecamatan Wera yang terletak disebelah utara Kabupaten Bima. Berikut adalah nilai akhir AHP dan indikator-indikator yang telah ditentukan pada kawasan embrio. 


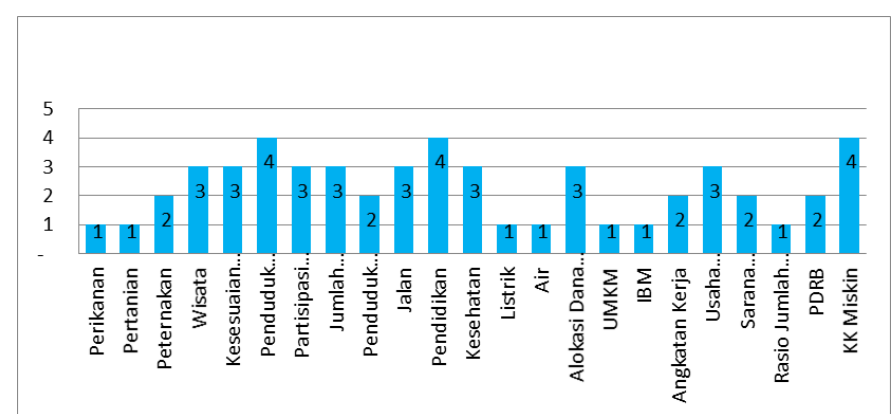

Gambar 4. Diagram Nilai Akhir Embrio Sumber : Hasil analisis,2018

Adapun nilai dominan berada pada indikator Pariwisata, Kesesuain Lahan, Partisipasi Masyarakat dalam Kelompok, Jumlah Kelompok Tani, Jalan, Pendidikan, Kesehatan, Alokasi Dana, Usaha Pariwisata, KK Miskin.

Berdasarkan nilai akhir tersebut, maka dapat disimpulkan bahwa Kecamatan Wera dikembangkan sebagai Kawasan Wisata. Kawasan wisata di Kecamatan Wera yang dimana dalam pembagian termasuk dalam klaster 2 berada pada kuadran II dan III Tipologi Klassen dengan pola dan Struktur pertumbuhan sektor ekonomi maju tapi tertekan dan sector potensial atau masih dapat berkembang dengan pesat. Adapun dalam Tipologi Klassen, kuadran II dan III bermakna sebagai berikut :

- $\quad$ Sektor maju tapi tertekan (Kuadran II). Sektor yang berada pada kuadran ini memiliki nilai pertumbuhan PDRB (gi) yang lebih rendah dibandingkan pertumbuhan PDRB daerah yang menjadi acuan atau secara nasional (g), tetapi memiliki kontribusi terhadap PDRB daerah (si) yang lebih besar dibandingkan kontribusi nilai sektor tersebut terhadap PDRB daerah yang menjadi acuan atau secara nasional (s). Klasifikasi ini biasa dilambangkan dengan gi $<$ g dan si $>$ s. Sektor dalam kategori ini juga dapat dikatakan sebagai sector yang telah jenuh.

- Sektor potensial atau masih dapat berkembang dengan pesat (Kuadran III). Kuadran ini merupakan kuadran untuk sektor yang memiliki nilai pertumbuhan PDRB (gi) yang lebih tinggi dari pertumbuhan PDRB daerah yang menjadi acuan atau secara nasional (g), tetapi kontribusi sektor tersebut terhadap PDRB (si) lebih kecil dibandingkan nilai kontribusi sektor tersebut terhadap PDRB daerah yang menjadi acuan atau secara nasional (s). Klasifikasi ini biasa dilambangkan dengan gi $>$ g dan si < s. Sektor dalam Kuadran III dapat diartikan sebagai sektor yang sedang booming. Meskipun pangsa pasar daerahnya relatif lebih kecil dibandingkan rata-rata nasional.

Berikut adalah strategi penataan ruang a. Mengembangkan dan menata kawasan pariwisata sebagai destinasi wisata Kabupaten;

b. Menyediakan prasarana dasar berupa drainase, persampahan, pengelolaan air limbah, jalan pejalan kaki yang memadai sesuai dengan standar pelayanan minimum di setiap destinasi pariwisata;

c. Mengembangkan inovasi dalam promosi pariwisata, melalui penyediaan paket-paket pariwisata terpadu lintas wilayah;

d. Meningkatkan kapasitas pemerintah, dukungan swasta, dan peran serta masyarakat dalam melaksanakan regulasi dan mekanisme operasional yang efektif dan efisien di sektor kepariwisataan;

e. Melestarikan seni, adat istiadat, budaya, kuliner khas daerah, dan situs kepurbakalaan, dan kawasan bernilai sejarah sebagai aset pariwisata;

f. Mengembangkan kegiatan perdagangan dan jasa serta industri kerajinan untuk mendukung industri pariwisata.

\section{Rencana Pengembangan Klaster \\ a. Rencana Pengembangan Klaster 1}

Klaster 1 terdiri dari Kecamatan Bolo, Kecamatan Soromandi, dan Kecamatan Donggo. Nilai akhir AHP dan indikator-indikator yang telah ditentukan pada klaster 1 dapat dilihat pada gambar 5 .

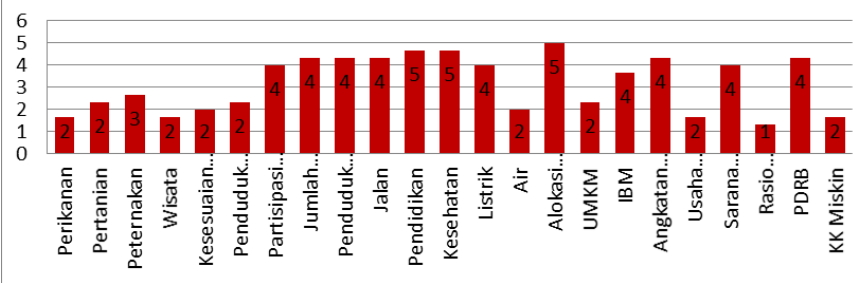

Gambar 5. Diagram Nilai Akhir Klaster 1 Sumber : Hasil analisis,2018

Adapun nilai dominan berada pada indikator Partisipasi Masyarakat, Jumlah Kelompok Tani, Penduduk Usia Produktif, Jalan, Pendidikan, Kesehatan, Listrik, Air, Alokasi Dana Desa, IBM, Angkatan Kerja, Sarana Perdagangan dan Niaga, serta PDRB.

Berdasarkan nilai akhir tersebut, maka dapat disimpulkan bahwa Klaster 1 dikembangkan sebagai Kawasan Industri. Adapun dalam klaster ini terdapat pusat kegiatan berdasarkan analisis skalogram dengan perkembangan wilayah berkembang pesat (Hirarki I) yaitu Kecamatan Bolo, dengan demikian Kecamatan Bolo merupakan pusat pertumbuhan pada Klaster 1.

Berikut adalah strategi penataan ruang Klaster 1.

a. Mengembangkan industri pengolahan yang berwawasan lingkungan;

b. Mengembangkan sentra-sentra industri kerajinan penunjang kegiatan pariwisata;

c. Menggunakan teknologi ramah lingkungan dalam operasional kegiatan industri;

Kecamatan Ambalawi. 
d. Menyediakan prasarana dasar berupa drainase, persampahan, dan pengelolaan air limbah yang memadai;

e. Merelokasi dan/atau meminimalisir dampak lingkungan yang terjadi akibat industri pengolahan dan industri kerajinan; dan

f. Mengembangkan zona penyangga antara kawasan industri dengan kawasan permukiman.

\section{b. Rencana Pengembangan Klaster 2}

Klaster 2 terdiri dari Kecamatan Woha, Kecamatan Palibelo, dan Kecamatan Belo. Berikut adalah nilai akhir AHP dan indikator-indikator yang telah ditentukan pada klaster 2.

\section{HhHHHhH||

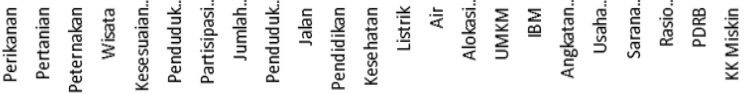

Gambar 6. Diagram Nilai Akhir Klaster 2 Sumber : Hasil analisis,2018

Adapun nilai dominan berada pada indikator Kesesuaian Lahan, Jumlah Kelompok Tani, Jalan, Pendidikan, Kesehatan, Listrik, Alokasi Dana Desa, Sarana Perdagangan dan Niaga, KK Miskin. Berdasarkan nilai akhir tersebut, maka dapat disimpulkan bahwa Klaster 2 dikembangkan sebagai Kawasan Perdagangan dan Niaga. Adapun dalam klaster ini terdapat pusat kegiatan berdasarkan analisis skalogram dengan perkembangan wilayah berkembang (Hirarki II) yaitu Kecamatan Woha, dengan demikian pusat pertumbuhan Klaster 2 berada di Kecamatan Woha. Selain itu, Kecamatan Woha merupakan pusat ibukota Kabupaten Bima sehingga klaster 2 merupakan klaster pusat pelayanan dengan produksi kawasan perdagangan dan niaga. Kawasan perdagangan dan niaga di klaster 2 yang dimana dalam pembagian termasuk dalam klaster 2 berada pada kuadran II Tipologi Klassen dengan pola dan Struktur pertumbuhan sektor ekonomi maju tapi tertekan. Adapun dalam Tipologi Klassen, kuadran II bermakna sektor yang berada pada kuadran ini memiliki nilai pertumbuhan PDRB (gi) yang lebih rendah dibandingkan pertumbuhan PDRB daerah yang menjadi acuan atau secara nasional (g), tetapi memiliki kontribusi terhadap PDRB daerah (si) yang lebih besar dibandingkan kontribusi nilai sektor tersebut terhadap PDRB daerah yang menjadi acuan atau secara nasional (s). Klasifikasi ini biasa dilambangkan dengan gi < g dan si $>$ s. Sektor dalam kategori ini juga dapat dikatakan sebagai sector yang telah jenuh. Berikut adalah strategi penataan ruang Klaster 2.

a. Mengembangkan fasilitas-fasilitas perkotaan secara merata sesuai dengan fungsi pelayanan, daya dukung, dan daya tampung wilayah; b. Mengembangkan system transportasi secara berjenjang yang menghubungkan pusat-pusat pelayanan kabupaten serta system jaringan prasarana lainnya;

c. Revitalisasi pusat pelayanan kabupaten yang lama serta mengembangkan pusat pelayanan kabupaten yang baru dengan fungsi primer dan fungsi sekunder;

d. Mengembangkan Subpusat Pelayanan Wilayah yang dilengkapi dengan prasarana dan sarana pendukung; dan

e. Mengembangkan Pusat Kegiatan Lingkungan di beberapa kecamatan yang mendukung pusat pelayanan wilayah dan subpusat pelayanan wilayah baik di bidang social maupun ekonomi.

f. Menata dan merevitaliasasi kawasan perdagangan dan jasa;

g. Mengembangkan sentra perdagangan dan jasa skala internasional, nasional, regional, dan lokal;

h. Meningkatkan aksesibilitas dari dan ke kawasan perdagangan dan jasa;

i. Mengembangkan aktivitas perdagangan dan jasa baru di pusat-pusat pertumbuhan;

j. Menyediakan ruang parkir yang memadai di setiap kawasan perdagangan;

k. Meminimalisir penetrasi kegiatan perdagangan pada kawasan perumahan;

l. Menyediakan prasarana drainase, persampahan, dan pengelolaan air limbah yang memadai pada kawasan pusat-pusat perdagangan;

m. Menyediakan prasarana dan sarana memadai bagi pejalan kaki dan pesepeda di kawasan perdagangan dan jasa; dan

n. Menyediakan dan mengoptimalkan fungsi RTH pada kawasan perdagangan dan jasa.

\section{c. Rencana Pengembangan Klaster 3}

Klaster 3 terdiri dari Kecamatan Monta, dan Kecamatan Langgudu. Berikut adalah nilai akhir AHP dan indikator-indikator yang telah ditentukan pada klaster 3 .

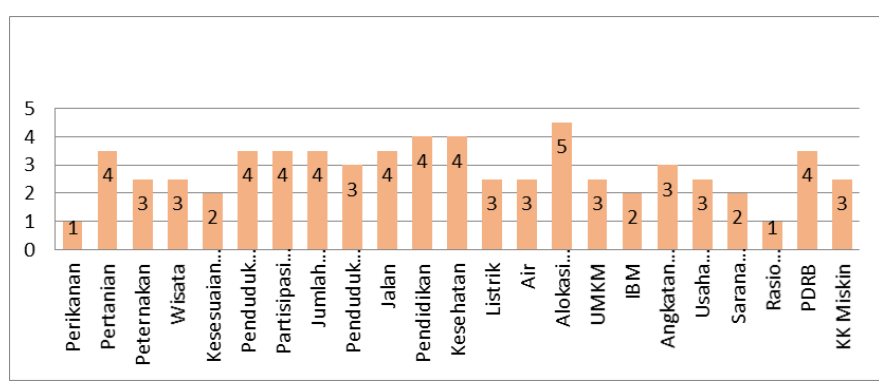

Gambar 7. Diagram Nilai Akhir Klaster 3 Sumber : Hasil analisis,2018

Adapun nilai dominan berada pada indikator Pertanian, Penduduk Tamatan SMA ke Atas, Partisipasi 
masyarakat dalam Kelompok Tani, Jalan, Pendidikan, Kesehatan, Alokasi Dana Desa, dan PDRB.

Berdasarkan nilai akhir tersebut, maka dapat disimpulkan bahwa Klaster 3 dikembangkan sebagai Kawasan Pertanian. Kawasan pertanian di klaster 3 yang dimana dalam pembagian termasuk dalam klaster 3 berada pada kuadran II Tipologi Klassen dengan pola dan Struktur pertumbuhan sektor ekonomi maju tapi tertekan. Adapun dalam Tipologi Klassen, kuadran II bermakna sektor yang berada pada kuadran ini memiliki nilai pertumbuhan PDRB (gi) yang lebih rendah dibandingkan pertumbuhan PDRB daerah yang menjadi acuan atau secara nasional (g), tetapi memiliki kontribusi terhadap PDRB daerah (si) yang lebih besar dibandingkan kontribusi nilai sektor tersebut terhadap PDRB daerah yang menjadi acuan atau secara nasional (s). Klasifikasi ini biasa dilambangkan dengan gi $<\mathrm{g}$ dan si $>\mathrm{s}$. Sektor dalam kategori ini juga dapat dikatakan sebagai sector yang telah jenuh.

Pada klaster 3, yang menjadi pusat pertumbuhan adalah Kecamatan Monta yang didasarkan pada hasil analisis skalogram. Berikut adalah strategi penataan ruang Klaster 3.

a. Menginventarisasi lahan dan pemilik lahan pertanian serta potensi kebutuhan air baku bagi pertanian;

b. Mengembangkan lahan pertanian menjadi lahan pertanian hortikultura dengan pemanfaatan sebagai RTH dan tempat wisata;

c. Mengembangkan prasarana dan sarana non irigasi dengan teknologi alternatif sesuai kebutuhan dan kondisi geografis; dan

d. Mengembangkan produk pertanian unggulan yang berorientasi agroindustri

\section{d. Rencana Pengembangan Klaster 4}

Klaster 4 terdiri dari Kecamatan Lambitu, dan Kecamatan Wawo. Berikut adalah nilai akhir AHP dan indikator-indikator yang telah ditentukan pada klaster 4 .

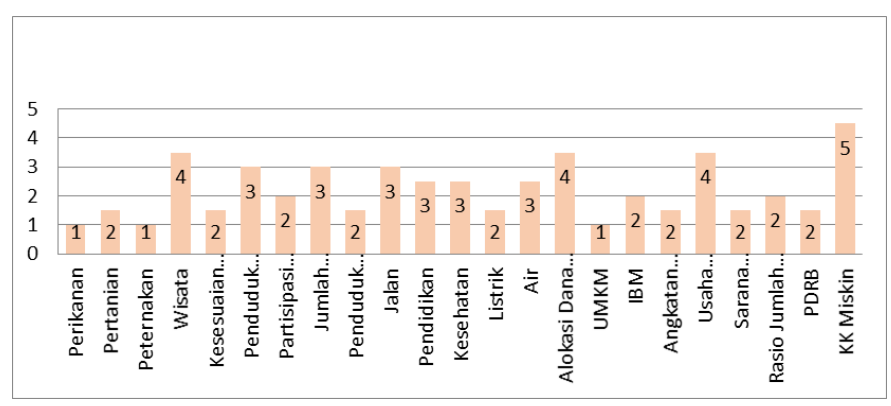

Gambar 8. Diagram Nilai Akhir Klaster 4 Sumber : Hasil analisis,2018

Adapun nilai dominan berada pada indikator Wisata, Alokasi Dana Desa, Usaha Pariwisata, dan KK Miskin. Berdasarkan nilai akhir tersebut, maka dapat disimpulkan bahwa Klaster 4 dikembangkan sebagai Kawasan Wisata. Bedanya dengan kawasan wisata pada Embrio, kawasan wisata pada Klaster 4 merupakan kawasan wisata yang diarahkan pada wisata cagar budaya. Hal ini dikarenakan potensi wisata utama klaster ini berupa banyaknya cagar budaya yang ada.
Kawasan wisata di Klaster 4 yang dimana dalam pembagian termasuk dalam klaster 4 berada pada kuadran II dan III Tipologi Klassen dengan pola dan Struktur pertumbuhan sektor ekonomi maju tapi tertekan dan sector potensial atau masih dapat berkembang dengan pesat. Adapun dalam Tipologi Klassen, kuadran II dan III bermakna sebagai berikut :

- Sektor maju tapi tertekan (Kuadran II). Sektor yang berada pada kuadran ini memiliki nilai pertumbuhan PDRB (gi) yang lebih rendah dibandingkan pertumbuhan PDRB daerah yang menjadi acuan atau secara nasional (g), tetapi memiliki kontribusi terhadap PDRB daerah (si) yang lebih besar dibandingkan kontribusi nilai sektor tersebut terhadap PDRB daerah yang menjadi acuan atau secara nasional (s). Klasifikasi ini biasa dilambangkan dengan gi $<$ g dan si $>$ s. Sektor dalam kategori ini juga dapat dikatakan sebagai sector yang telah jenuh.

- Sektor potensial atau masih dapat berkembang dengan pesat (Kuadran III). Kuadran ini merupakan kuadran untuk sektor yang memiliki nilai pertumbuhan PDRB (gi) yang lebih tinggi dari pertumbuhan PDRB daerah yang menjadi acuan atau secara nasional (g), tetapi kontribusi sektor tersebut terhadap PDRB (si) lebih kecil dibandingkan nilai kontribusi sektor tersebut terhadap PDRB daerah yang menjadi acuan atau secara nasional (s). Klasifikasi ini biasa dilambangkan dengan gi $>$ g dan si $<$ s. Sektor dalam Kuadran III dapat diartikan sebagai sektor yang sedang booming. Meskipun pangsa pasar daerahnya relatif lebih kecil dibandingkan rata-rata nasional.

Pada klaster 4, yang menjadi pusat pertumbuhan adalah Kecamatan Lambitu yang didasarkan pada hasil analisis skalogram. Berikut adalah strategi penataan ruang Klaster 4.

a. Mengembangkan dan menata kawasan pariwisata sebagai destinasi wisata Kabupaten;

b. Menyediakan prasarana dasar berupa drainase, persampahan, pengelolaan air limbah, jalan pejalan kaki yang memadai sesuai dengan standar pelayanan minimum di setiap destinasi pariwisata;

c. Mengembangkan inovasi dalam promosi pariwisata, melalui penyediaan paket-paket pariwisata terpadu lintas wilayah;

d. Meningkatkan kapasitas pemerintah, dukungan swasta, dan peran serta masyarakat dalam melaksanakan regulasi dan mekanisme operasional yang efektif dan efisien di sektor kepariwisataan;

e. Melestarikan seni, adat istiadat, budaya, kuliner khas daerah, dan situs kepurbakalaan, dan kawasan bernilai sejarah sebagai aset pariwisata;

f. Mengembangkan kegiatan perdagangan dan jasa serta industri kerajinan untuk mendukung industri pariwisata. 
g. Melakukan konservasi terhadap bangunan dan lingkungan bersejarah dan/atau bernilai arsitektur tinggi;

h. Melestarikan dan mengembangkan serta potensi sosial budaya masyarakat yang memiliki nilai sejarah;

i. Merevitalisasi kawasan-kawasan yang mendukung pencitraan kabupaten berwawasan budaya lokal;

j. Menyelaraskan kegiatan-kegiatan budidaya yang tidak mengganggu fungsi kawasan cagar budaya

\section{e. Rencana Pengembangan Klaster 5}

Klaster 5 terdiri dari Kecamatan Sape, dan Kecamatan Lambu. Berikut adalah nilai akhir AHP dan indikator-indikator yang telah ditentukan pada klaster 5 .

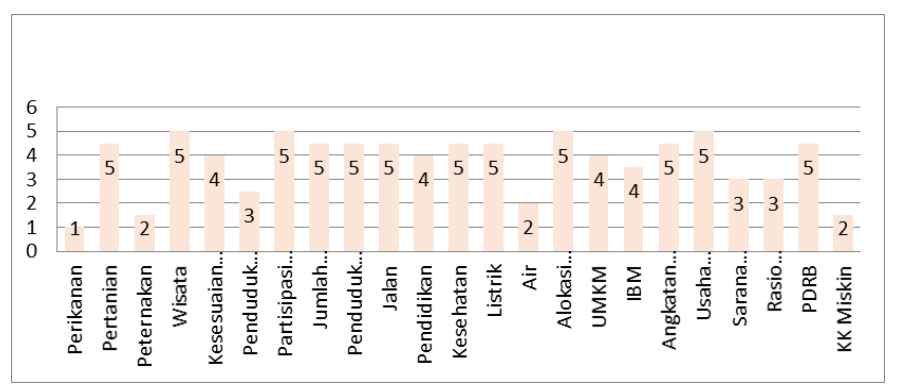

Gambar 9. Diagram Nilai Akhir Klaster 5 Sumber : Hasil analisis,2018

Adapun nilai dominan berada pada indikator Pertanian, Wisata, Kesesuaian Lahan, Partisipasi Masyarakat dalam Kelompok, Jumlah Kelompok Tani, Penduduk Usia Produktif, Jalan, Pendidkan, Kesehatan, Listrik, Alokasi Dana Desa, UMKM, IBM, Angkatan Kerja, Usaha pariwisata, dan PDRB Berdasarkan nilai akhir tersebut, maka dapat disimpulkan bahwa Klaster 5 dikembangkan sebagai Kawasan Wisata. Bedanya dengan kawasan wisata pada Embrio dan kawasan wisata pada klaster 3, kawasan wisata pada Klaster 4 merupakan kawasan wisata yang diarahkan pada wisata lintas kabupaten dan provinsi. Hal ini dikarenakan potensi wisata utama klaster ini berupa wisata transit menuju kawasan wisata di Pulau Komodo Provinsi Nusa Tenggara Timur. Adapun dalam klaster ini terdapat pusat kegiatan berdasarkan analisis skalogram dengan perkembangan wilayah berkembang (Hirarki II) yaitu Kecamatan Sape, dengan demikian pusat pertumbuhan Klaster 5 berada di Kecamatan Sape. Kawasan wisata di Klaster 5 yang dimana dalam pembagian termasuk dalam klaster 5 berada pada kuadran II dan III Tipologi Klassen dengan pola dan Struktur pertumbuhan sektor ekonomi maju tapi tertekan dan sector potensial atau masih dapat berkembang dengan pesat. Adapun dalam Tipologi Klassen, kuadran II dan III bermakna sebagai berikut :

- Sektor maju tapi tertekan (Kuadran II). Sektor yang berada pada kuadran ini memiliki nilai pertumbuhan PDRB (gi) yang lebih rendah dibandingkan pertumbuhan PDRB daerah yang menjadi acuan atau secara nasional (g), tetapi memiliki kontribusi terhadap PDRB daerah (si) yang lebih besar dibandingkan kontribusi nilai sektor tersebut terhadap PDRB daerah yang menjadi acuan atau secara nasional (s). Klasifikasi ini biasa dilambangkan dengan gi $<\mathrm{g}$ dan $\mathrm{si}>\mathrm{s}$. Sektor dalam kategori ini juga dapat dikatakan sebagai sector yang telah jenuh.

- Sektor potensial atau masih dapat berkembang dengan pesat (Kuadran III). Kuadran ini merupakan kuadran untuk sektor yang memiliki nilai pertumbuhan PDRB (gi) yang lebih tinggi dari pertumbuhan PDRB daerah yang menjadi acuan atau secara nasional (g), tetapi kontribusi sektor tersebut terhadap PDRB (si) lebih kecil dibandingkan nilai kontribusi sektor tersebut terhadap PDRB daerah yang menjadi acuan atau secara nasional (s). Klasifikasi ini biasa dilambangkan dengan gi $>$ g dan si $<$ s. Sektor dalam Kuadran III dapat diartikan sebagai sektor yang sedang booming. Meskipun pangsa pasar daerahnya relatif lebih kecil dibandingkan rata-rata nasional.

Berikut adalah strategi penataan ruang Klaster 5 .

a. Mengembangkan dan menata kawasan pariwisata sebagai destinasi wisata Kabupaten;

b. Menyediakan prasarana dasar berupa drainase, persampahan, pengelolaan air limbah, jalan pejalan kaki yang memadai sesuai dengan standar pelayanan minimum di setiap destinasi pariwisata;

c. Mengembangkan inovasi dalam promosi pariwisata, melalui penyediaan paket-paket pariwisata terpadu lintas wilayah;

d. Meningkatkan kapasitas pemerintah, dukungan swasta, dan peran serta masyarakat dalam melaksanakan regulasi dan mekanisme operasional yang efektif dan efisien di sektor kepariwisataan;

e. Melestarikan seni, adat istiadat, budaya, kuliner khas daerah, dan situs kepurbakalaan, dan kawasan bernilai sejarah sebagai aset pariwisata;

f. Mengembangkan kegiatan perdagangan dan jasa serta industri kerajinan untuk mendukung industri pariwisata.

\section{f. Rencana Pengembangan Klaster 6}

Klaster 6 terdiri dari Kecamatan Tambora, dan Kecamatan Sanggar. Telah ditetapkan sebagai Geopark Nasional TAMBORA, sehingga selain fungsi konservasi dan edukasi, penetapan Geopark Nasional Gunung Tambora diyakini dapat meningkatkan kesejahteraan dan menumbuhkan embrio ekonomi lokal melalui pengembangan sektor pariwisata berbasis kegiatan ecotourism dan agrowisata. Pada klaster 6, yang menjadi pusat pertumbuhan adalah Kecamatan Tambora yang didasarkan pada hasil analisis skalogram. Berikut adalah strategi penataan ruang Klaster 6. 
a. Melestarikan peninggalan nilai keragaman geologi, nilai arkeologi, nilai ekologi, dan nilai sejarah atau budaya untuk generasi saat ini dan masa depan;

b. Mendidik dan mengajar masyarakat luas mengenai isu-isu dalam ilmu geologi dan kaitannya dengan permalasahan lingkungan;

c. Memastikan pembangunan sosio-ekonomi dan budaya yang berkelanjutan;

d. Membangun jembatan multi-budaya untuk warisan dan konservasi dan pemeliharaan perbedaan budaya dan geologi, menggunakan skema partisipasi dan copartnership;

e. Merangsang penelitian, dan

f. Memberikan kontribusi secara aktif terhadap kehidupan jaringan melalui kerjasama inisiatif (komunikasi, publikasi, pertukaran informasi, dsb).

\section{SIMPULAN DAN SARAN}

Permendagri Nomor 29 Tahun 2008 memberikan salah satu pilihan bagi daerah untuk membangun daerahnya melalui pendekatan pengembangan daerahnya berupa Kawasan Strategis dan Cepat Tumbuh (KSCT), yang sesuai dengan kondisi, kekhasan, dan potensi unggulan daerah yang pada akhirnya mampu memperkuat daya saing perekonomian. Permendagri hanya merupakan sarana untuk pendorong percepatan pengembangan kawasan yang berpotensi sebagai pusat pertumbuhan wilayah yang telah berkembang atau potensial berkembang, mengurangi kesenjangan pembangunan antar wilayah dan mendorong daerah perbatasan, pesisir dan pulau-pulau kecil, serta mengoptimalkan pemanfaatan komparatif dan kompetitif sektor/produk unggulan daerah dan daya tarik kawasan di pasar lokal maupun domestik.

Berdasarkan Rencana Tata Ruang Nasional, Provinsi, dan Kabupaten, terdapat beberapa kawasan-kawasan strategis yaitu, kawasan strategis nasional, kawasan strategis provinsi, dan kawasan strategis kabupaten yang akan menjadi pusat pertumbuhan dan pengembangan wilayah. Kawasan strategis cepat tumbuh ditandai dengan pertumbuhan disektor ekonomi yang relatif berkembang, terbangun infrastruktur pendukung yang memadai serta tingkat kesejahteraan masyarakat yang cenderung berkembang dan meningkat.

Pedoman penyusunan identifikasi Kawasan Strategis Cepat Tumbuh Kabupaten Bima tidak terlepas dari Peraturan Menteri Dalam Negeri No. 29 Tahun 2008 tentang Pengembangan Kawasan Strategis Cepat Tumbuh di Daerah. Dalam peraturan tersebut disebutkan bahwa Kawasan Strategis Cepat Tumbuh terdiri dari 3 (tiga) buah rencana yaitu, Rencana Induk, Rencana Pengusahaan, dan Rencana Tindak. Pada rencana induk terdiri dari :

1. Hasil kajian menyeluruh terhadap semua aspek kunci pengembangan KSCT sebagai data dasar; dan

2. Proyeksi arah, skenario, dan tahapan pengembangan kawasan dalam jangka menengah.
Kemudian 2 (dua) rencana lainnya yaitu, rencana pengusahaan dan rencana tindak disusun berdarkan hasil rencana induk. Pada tahapan identifikasi ini baru melaksanakan pada point (1) yaitu mengkaji semua aspek kunci pengembangan KSCT yang tertuang di dalam indikator-indikator sosial, ekonomi, dan lingkungan.

Seiring perkembangan dan pertumbuhan wilayah Kabupaten Bima serta pemanfaatan ruang yang tidak terkendali sehingga terbentuk pusat-pusat pertumbuhan baru yang tersebar diberbagai wilayah kabupaten. Dalam rangka mendorong percepatan pengembangan kawasan tersebut, mengurangi kesenjangan pembangunan antar wilayah, dan mendorong pertumbuhan daerah yang masih tertinggal dan perbatasan di Kabupaten Bima, sehingga diperlukan tindakan lebih lanjut setelah Kawasan Strategis Cepat Tumbuh di Kabupaten Bima yaitu, penyusunan Rencana Induk, Rencana Pengusahaan, dan Rencana Tindak sebagai upaya mendorong percepatan pengembangan kawasan yang berpotensi sebagai pusat pertumbuhan wilayah yang telah berkembang atau potensial berkembang, mengurangi kesenjangan pembangunan antar wilayah dan mendorong daerah perbatasan, pesisir dan pulaupulau kecil, serta mengoptimalkan pemanfaatan komparatif dan kompetitif sektor/produk unggulan daerah dan daya tarik kawasan di pasar lokal maupun domestik.

\section{Daftar Rujukan}

[1] D. Widiarsih, "Pengembangan Wilayah Kawasan Strategis Cepat Tumbuh (KSCT) Kota," Jurnal Akuntansi dan Ekonomika, vol. 7, no. 2, pp. 132-139, 2017.

[2] Kementerian Dalam Negeri Republik Indonesia, Peraturan Menteri Dalam Negeri No. 29 Tahun 2008 Tentang Pengembangan Kawasan Strategis Cepat Tumbuh di daerah (KSCT), Jakarta: KEMENDAGRI, 2008.

[3] S. H. W. M. E.Rustiadi dan Hadi, Kawasan Agropolitan : Konsep Membangun Desa-Kota Berimbang, Crestpent Press, 2006.

[4] Pemerintah Indonesia, Undang-Undang No. 26 Tahun 2007 Tentang Penataan Ruang., Jakarta: Sekretariat Negara, 2006. 